\title{
Maratonas hackers no Brasil com desafios no campo da Saúde
}

\author{
Francini Lube Guizardi(a) \\ Karina Fernandes dos Santos ${ }^{(b)}$ \\ Ana Silvia Pavani Lemos ${ }^{(c)}$ \\ Fernanda Maria Duarte Severo ${ }^{(\mathrm{d})}$
}

Guizardi FL, Santos KF, Lemos ASP, Severo FMD. Hackathons in Brazil and the challenges they pose to the field of health. Interface (Botucatu). 2018; 22(65):447-59.

The objective of this study was to map the carrying out of hacking marathons in Brazil, and the challenges they pose to the field of health. The expectation is that the description and presentation of the methodological aspects of the mapped events, along with information drawn from the literature, may help in the dissemination of the methodology and its application to the health sector. The mapping was exploratory and descriptive and was carried out through an internet search, using Google and the Virtual Health Library (BVS) database, covering the period between 2000 and 2016. The researchers identified 16 hackathons, all of which occurred after 2012, and which presented challenges and solutions to health. The results point to the potential of this methodology as a means of promoting creativity and innovation, based on collaborative work by teams of professionals from different areas for identifying timely solutions to the health field.

Keywords: Hackathon. Methodology. Health. Collaboration. Innovation in Health.
O objetivo deste estudo foi mapear a realização de maratonas hackers no Brasil, com desafios voltados para o campo da Saúde. Espera-se que a descrição e sistematização dos aspectos metodológicos dos eventos identificados, cotejados com informações advindas de levantamento bibliográfico, auxiliem na divulgação e aplicação da metodologia na saúde. De caráter exploratório e descritivo, o mapeamento foi realizado por meio de uma pesquisa web, com o buscador Google, e na base de dados Biblioteca Virtual da Saúde (BVS), abrangendo o período entre 2000 e 2016. Identificou-se a realização de 16 hackathons que abordaram desafios ou soluções na Saúde, sendo todos realizados a partir de 2012. Os resultados encontrados ressaltam o potencial da metodologia como fomento à criatividade e à inovação, a partir do trabalho colaborativo em equipe multiprofissional para soluções oportunas no campo da Saúde.

Palavras-chave: Hackathon. Metodologia. Saúde. Colaboração. Inovação em Saúde.

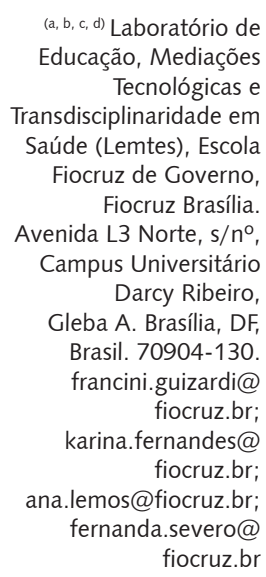




\section{Introdução}

Maratonas hackers, também conhecidas como hackathons, festas hackers ou festival hackers (hackfest, hacking festival), são eventos que emergiram na área de tecnologia com a característica central de engajar diferentes profissionais em um trabalho colaborativo, de natureza intensiva, realizado em curto período de tempo e com foco em determinado problema ou desafio. A palavra "hackathon" vem da combinação das palavras "hack" e "marathon" e significa uma longa corrida para criar algo útil em um único evento ${ }^{1,2}$.

A inovação é um aspecto central dessa metodologia, que busca mobilizar e desafiar seus participantes a apresentarem coletivamente respostas e soluções pioneiras, geralmente na área de programação e desenvolvimento de softwares ${ }^{3-6}$. A efetividade do fenômeno hackathon na inovação digital pode ser atestada por sua popularização em indústrias e instituições, públicas e privadas², uma tendência manifesta na ampliação expressiva de sua realização ao longo dos anos 2000. Nessa década, as maratonas hackers disseminaram-se como uma metodologia efetiva para rápido desenvolvimento de novos softwares e para identificação de áreas de inovação e investimento ${ }^{3,4,6}$. Nesse contexto, o Drupal e a MediaWiki são exemplos de plataformas que tiveram desenvolvimento potencializado por maratonas hackers ${ }^{2}$.

Segundo Briscoe e Mulligan², o fenômeno hackathon tem uma ocorrência global, tendo se desenvolvido de festas improvisadas a eventos corporativos organizados e financiados por empresas de softwares como Google e Facebook. Entretanto, o crescimento empresarial de sua utilização gerou tensionamento em relação às suas características iniciais, orientadas por desafios sociais e valores de cidadania, como no caso civic hacking(e) e do data activism $^{(f)}$.

As maratonas, inicialmente focadas no desenvolvimento técnico de códigos e programas, passaram a ser utilizadas também como estratégia para construção de soluções em interface com outros campos, como a música, as artes, gestão pública e conhecimento científico. Constata-se a expansão de sua aplicação por parte de organizações da sociedade civil e instituições governamentais², em especial, como suporte a ferramentas de gestão democráticas (open government) e no enfrentamento dos problemas de inclusão social de grupos vulneráveis².

Reconhecendo esse movimento, Li e Johnson ${ }^{4}$ sinalizam que a metodologia de maratonas hackers pode ser direcionada para inovação e melhoria de respostas a questões sociais, ampliando a visibilidade e a consciência. Linnell et al. ${ }^{3}$ consideram que hackathons voltados para questões sociais geram maior adesão de parceiros da sociedade civil.

Apesar do crescimento de informações e experiências relacionadas a essa metodologia, observa-se que a produção acadêmica sobre o tema ainda é incipiente, sendo composta majoritariamente por relatos de experiências de sua aplicação a campos e temáticas específicos². Na área da Saúde, há poucas publicações descrevendo as maratonas hackers; dentre os achados, destaca-se a elaboração de soluções tecnológicas para pesquisas em Genética e Filogenia ${ }^{5}$, na Medicina ${ }^{4,6}$ e na educação interprofissional ${ }^{7}$.

Considerando essa lacuna, incompatível com a relevância da metodologia para o desenvolvimento de inovações tecnológicas e sociais, o objetivo deste artigo é mapear a realização de maratonas hackers no Brasil, organizadas com desafios voltados para o campo da Saúde. A pesquisa buscou identificar eventos planejados segundo essa metodologia, a fim de analisar suas características e de refletir sobre o seu potencial. Espera-se que a descrição e sistematização dos aspectos metodológicos dos eventos identificados, cotejados com informações (e) Processo colaborativo para criação de soluções de dados abertos, com base em informações e bancos de dados públicos, códigos e tecnologias, a fim de resolver desafios locais, de caráter social, econômico ou ambiental. Fonte: https://en.wiktionary. org/wiki/civic_hacker.

(f) Tipo específico de ativismo que utiliza a produção e coleção de dados digitais e de códigos-fontes abertos para desafiar relações de poder existentes. Fonte: https://en.wikipedia. org/wiki/Data_Activism. 
advindas da literatura sobre o tema, auxiliem na divulgação e aplicação das maratonas hackers na Saúde.

\section{História das maratonas hackers}

Acredita-se que o termo hackathon tenha surgido em 1999, de forma independente, em duas experiências quase simultâneas: o open-source software developers of the Open BSD computer operating system e o Sun Microsystems Marketers ${ }^{8}$. No primeiro evento, ocorrido em 4 de junho de 1999, um pequeno grupo de desenvolvedores reuniu-se para encontrar soluções a fim de evitar problemas legais relacionados à criptografia e à exportação de dados a partir dos Estados Unidos da América. O segundo encontro foi realizado no Java One Conference, entre 15 e 19 de junho desse mesmo ano, e o desafio era criar um programa de computador na linguagem Java, a fim de viabilizar uma intranet com comunicação com outros dispositivos conectados à internet ${ }^{9}$.

Essas experiências buscavam uma atividade dinâmica, como uma maratona, para criar algo aplicável e livre", elementos implicados à própria cultura hacker. "A Ética Hacker centraliza-se em torno do princípio de que aquela informação deve ser livre [como no discurso], e a pessoa deve ter liberdade de repropor os dispositivos do dia a dia em novas e inesperadas formas [...]"2.

Embora as experiências inaugurais tenham ocorrido na década de 1990, a palavra "hack" está relacionada com a evolução do computador, que, por sua vez, associa-se à história da cultura hacker. Ainda em 1975, em um ambiente de experimentação e apresentação de ideias, um grupo se reunia quinzenalmente para criar uma máquina acessível a "cidadãos comuns": o computador pessoal. Constituiu-se, assim, o Homebrew Computer Club, que contou com o criador do primeiro computador portátil, Adam Osbornne, além do criador dos computadores Apple I e Apple II, Wozniak $^{10}$. O Homebrew Computer Club é um marco significativo da cultura hacker por engendrar o desenvolvimento transformador dos padrões de produção, instigando a inovação e reconhecendo-a como desafiadora ${ }^{11}$.

Seguindo essas experiências, os elementos centrais das maratonas hackers consolidaram-se por mobilizar redes sociotécnico-locais, em festas informais, chamadas LAN parties. Nelas, os grupos reuniam-se para compartilhar melhorias e customizações em seus dispositivos tecnológicos². Vem dessa fase a incorporação ritual de bebidas energéticas para estimular as longas horas de trabalho que duravam toda a noite. Outra característica desses eventos é a informalidade, visto que muitas vezes a alimentação e o descanso ocorrem no próprio espaço das atividades. A intensividade e a informalidade do trabalho explicam porque um dos resultados mais valorizados em relação às maratonas hacker é o espírito de comunidade, que muitas vezes perdura após os eventos².

Tais experiências acabaram consagrando as principais características dessa metodologia: a reunião de pessoas engajadas pelo desenvolvimento tecnológico, a duração limitada das atividades e o compartilhamento de objetivos em atividades intensivas ${ }^{2}$. Briscoe e Mulligan² associam o formato à tradição das jam sessions musicais, reuniões informais para colaboração de expertises, mobilizada por músicos para criação e desenvolvimento de novos materiais. Nessa tradição, destaca-se a relação entre o caráter lúdico da experiência e a colaboração criativa, aspectos estruturantes da metodologia de maratona hackers.

\section{Percurso metodológico}

De cunho exploratório e descritivo, este estudo foi realizado a partir de uma pesquisa web nas bases de dados da BVS e no buscador do Google, com o objetivo de identificar a realização de hackathons com desafios no campo da Saúde, especificamente no Brasil. Compreendendo que tais maratonas começaram a ser realizadas por volta do segundo semestre de 1999, considerou-se como critério de inclusão sua realização no Brasil no período entre 2000 e 2016.

A busca na base de dados BVS visou identificar artigos sobre hackathons na área da Saúde realizados no Brasil. A pesquisa ocorreu no mês de abril de 2016, utilizando-se as palavras-chave "hackathon" e "saúde". Nesse levantamento, foram encontrados quatro artigos na língua inglesa, 
sendo um artigo com enfoque teórico e três artigos de relato de experiência, dos quais dois estavam em duplicidade e um não relacionado especificamente à área da Saúde. Apesar de envolver estudantes brasileiros, o artigo de relato de experiência da área da saúde não foi incluído nos resultados, por ter sido realizado nos Estados Unidos.

A pesquisa web foi primordial, face ao fato de a temática das maratonas hackers ocorrerem vinculadas a tecnologias web e ao ambiente virtual. A busca realizada no sistema Google filtrou diretamente páginas que apresentavam as palavras "hackathon" e "saúde". Em ferramentas específicas disponibilizadas no buscador, foram selecionados os itens "Brasil" e "português" para especificar campos "país" e "idioma". A especificação do ano foi feita a partir do campo "Intervalo personalizado". Considerou-se o intervalo de $1^{\circ}$ de janeiro a 31 de dezembro para cada ano averiguado, nos períodos entre 2000 e 2016.

Em um primeiro momento, o conjunto de achados foi contemplado em sua totalidade, tendo em vista o número restrito de fontes. A partir da leitura do conteúdo apresentado, foram selecionados aqueles que abordaram a temática Saúde em eventos utilizando a metodologia de hackathon, realizados no Brasil. Foram excluídos os eventos de pré-hackathons do resultado final.

A pesquisa web foi realizada duas vezes, em períodos diferentes, com o objetivo de melhor consolidar a verificação das maratonas. A primeira etapa foi realizada entre 5 e 20 de abril de 2016, e a segunda, entre $1^{\circ}$ de julho e 24 de outubro de 2016. Em relação ao ano 2016, foram consideradas as maratonas já realizadas e aquelas divulgadas para o segundo semestre.

\section{Resultados e discussão}

A partir dos critérios de seleção, foram identificadas 16 experiências brasileiras de maratonas hackers na área da Saúde, não havendo variação dos resultados nas duas etapas de busca. Não foram identificadas experiências prévias a 2012, demonstrando o caráter recente da utilização dessa metodologia na área da Saúde. Nos anos subsequentes, a distribuição dos achados se deu da seguinte forma: uma experiência em 2012; uma em 2013; cinco em 2014; quatro em 2015; e cinco em 2016, indicando um crescimento moderado e constante nos últimos três anos. O detalhamento de cada experiência está descrito no Quadro 1.

Parte dos hackathons apresentou seus desafios dentro de um escopo vinculado a questões referidas à sociedade, tendo a Saúde como elemento convergente, seja para a concepção das maratonas, seja pela premiação dada. É preciso destacar que a tipologia apresentada foi definida a partir da relação entre o tipo e a intencionalidade do desafio indicado pelos organizadores. Nesse sentido, foram identificadas seis maratonas com desafios no campo da Saúde. As outras dez apresentaram desafios no âmbito geral das políticas e da gestão pública, vinculando-se apenas indiretamente à Saúde.

Quadro 1. Detalhamento da realização de hackathons no Brasil com desafios no campo da Saúde

\begin{tabular}{|c|c|c|c|}
\hline Ano & Evento/Instituição & Especificidades metodológicas & Desafios propostos \\
\hline 2012 & $\begin{array}{l}\text { Desenvolvendo a } \\
\text { América Latina }{ }^{12} \\
\text { Fundação Cidadão } \\
\text { Inteligente }\end{array}$ & $\begin{array}{l}36 \text { horas de duração; premiação em } \\
\text { dinheiro; ocorrência simultânea em vários } \\
\text { países da América Latina; avaliação por júri } \\
\text { internacional; desenvolvimento posterior por } \\
\text { uma semana dos projetos vencedores. }\end{array}$ & $\begin{array}{l}\text { Desenvolver aplicativo com soluções } \\
\text { de alto impacto para Saúde, Educação, } \\
\text { seguridade, cidadania, gasto estatal, } \\
\text { pobreza, meio ambiente, entre outros. }\end{array}$ \\
\hline 2013 & $\begin{array}{l}\text { Hacker Cidadão }^{13} \\
\text { Campus Party Recife } \\
\mathrm{MCl} \text { Brasil S/A }\end{array}$ & $\begin{array}{l}\text { Cinco dias de duração; premiação em } \\
\text { equipamentos de informática. Compõe } \\
\text { estratégia de internacionalização do evento } \\
\text { Campus Party (Futura Networks). }\end{array}$ & $\begin{array}{l}\text { Desenvolver aplicativos web e de } \\
\text { celulares utilizando os dados abertos da } \\
\text { Prefeitura de Recife - contribui para a } \\
\text { qualidade de vida da população. }\end{array}$ \\
\hline
\end{tabular}


Quadro 1. continuação

\begin{tabular}{|c|c|c|c|}
\hline Ano & Evento/Instituição & Especificidades metodológicas & Desafios propostos \\
\hline \multirow{5}{*}{2014} & $\begin{array}{l}2^{\circ} \text { Hackathon }{ }^{14} \\
\text { CJE - Fiesp }\end{array}$ & $\begin{array}{l}\text { Dois dias de duração, de forma ininterrupta; } \\
\text { premiação em cursos, produto e inscrição em } \\
\text { evento; desenvolvimento posterior do projeto } \\
\text { vencedor. Apoio de mentores aos grupos. }\end{array}$ & $\begin{array}{l}\text { Apresentar produto ou projeto para } \\
\text { problemas nas áreas sociais, de Educação, } \\
\text { Saúde e segurança de São Paulo. }\end{array}$ \\
\hline & $\begin{array}{l}\text { 1a Maratona de } \\
\text { Programação e } \\
\text { Desenvolvimento } \\
\text { para Gestão do } \\
\text { Conhecimento em } \\
\text { Saúde } \\
\text { Fiocruz Brasília/Rebrats/ } \\
\text { EVIPNet Brasil }\end{array}$ & $\begin{array}{l}\text { Três dias de duração e avaliação baseada } \\
\text { em interesse público; criatividade; qualidade } \\
\text { técnica; e aplicabilidade no trabalho } \\
\text { desenvolvido pelos órgãos brasileiros de Saúde } \\
\text { Pública. Base de dados utilizada: Pesquisa } \\
\text { Saúde. }\end{array}$ & $\begin{array}{l}\text { Desenvolver soluções para dispositivos } \\
\text { móveis e web utilizando os dados da base } \\
\text { de dados aberta da Pesquisa Saúde. }\end{array}$ \\
\hline & $\begin{array}{l}3^{\circ} \text { Hackathon }^{16} \\
\text { CJE - Fiesp }\end{array}$ & $\begin{array}{l}\text { Dois dias de duração, de forma ininterrupta; } \\
\text { premiação em cursos, visitas técnicas, livros } \\
\text { e sessão de mentoring; programação com } \\
\text { palestras sobre temas induzidos, momento } \\
\text { específico para tempestade de ideias e para } \\
\text { formação das equipes. }\end{array}$ & $\begin{array}{l}\text { Criar solução para aplicativo, com código } \\
\text { aberto, tendo como categorias inovação } \\
\text { disruptiva para a sociedade e indústria } \\
\text { conectada. }\end{array}$ \\
\hline & $\begin{array}{l}\text { Desenvolvendo a } \\
\text { América Latina }{ }^{17} \\
\text { OKBR, Casa do } \\
\text { Desenvolvimento } \\
\text { Humano } \\
\text { Contemporâneo e Lab } \\
\text { Experimental. }\end{array}$ & $\begin{array}{l}\text { Dois dias de duração; premiação em dinheiro; } \\
\text { ocorrência simultânea em vários países } \\
\text { da América Latina; um mês de apoio ao } \\
\text { desenvolvimento do projeto vencedor após o } \\
\text { evento. }\end{array}$ & $\begin{array}{l}\text { Desenvolver aplicativos inovadores, } \\
\text { sustentáveis, escaláveis, abertos e de } \\
\text { alto impacto social - áreas de Educação, } \\
\text { Saúde, transporte e outras. }\end{array}$ \\
\hline & $\begin{array}{l}\text { Hack PUC } 18 \\
\text { PUC-RIO }\end{array}$ & $\begin{array}{l}\text { Três dias de duração; premiação em dinheiro; } \\
\text { Inscrição de times (até quatro pessoas), que } \\
\text { foram selecionados para participar. }\end{array}$ & $\begin{array}{l}\text { Construir soluções (web ou apps) para } \\
\text { resolver problemas sociais de utilidade } \\
\text { pública - áreas da Educação, Saúde ou } \\
\text { transporte. }\end{array}$ \\
\hline \multirow{4}{*}{2015} & $\begin{array}{l}\text { Hack SUS }{ }^{19} \\
\text { Ministério da Saúde }\end{array}$ & $\begin{array}{l}\text { Três dias de duração; equipes formadas } \\
\text { previamente; disponibilização de materiais e } \\
\text { manual de apoio. }\end{array}$ & $\begin{array}{l}\text { Desenvolver um protótipo (não funcional) } \\
\text { de um ambiente virtual para o SUS, } \\
\text { apresentando projeto com planejamento, } \\
\text { desenvolvimento e prototipação. }\end{array}$ \\
\hline & $\begin{array}{l}\text { Startup Hack }{ }^{20} \\
\text { Sebrae Minas }\end{array}$ & $\begin{array}{l}\text { Dois dias de duração; premiação: três meses } \\
\text { de aceleração, com espaço físico, internet } \\
\text { e mentoria; seleção dos participantes } \\
\text { baseada no perfil e nas melhores respostas } \\
\text { ao questionamento "Por que gostaria de } \\
\text { participar do hackathon?"; divisão aleatória } \\
\text { dos participantes em grupos de cinco pessoas; } \\
\text { curadoria da Associação Brasileira de Startups. }\end{array}$ & $\begin{array}{l}\text { Maratona de programação (Exchange } \\
\text { Sebrae) com o objetivo de criar soluções } \\
\text { que atendam às necessidades da Unimed- } \\
\text { BH. }\end{array}$ \\
\hline & $\begin{array}{l}\text { Hack4Health }{ }^{21} \\
\text { GE Healthcare }\end{array}$ & $\begin{array}{l}\text { Três dias de duração; premiação em } \\
\text { dinheiro; atividades previstas de mentorias, } \\
\text { apresentações, brainstorming e discussões } \\
\text { com convidados da comissão organizadora; } \\
\text { pós-evento: participar de um programa de } \\
\text { mentoring com a empresa Health } 2.0 \text { Latin } \\
\text { America por seis meses. }\end{array}$ & $\begin{array}{l}\text { Propor a melhor solução para os desafios } \\
\text { "Desospitalização" e "Redução de } \\
\text { custos e aumento de eficiência no setor } \\
\text { hospitalar". }\end{array}$ \\
\hline & $\begin{array}{l}\text { Let's GO22 } \\
\text { Secretaria de Estado de } \\
\text { Gestão e Planejamento } \\
\text { (GO) }\end{array}$ & $\begin{array}{l}\text { Cinco dias de duração; premiação: cursos e } \\
\text { vouchers de } 30 \text { dias para a plataforma Azure, } \\
\text { da Microsoft. As equipes foram formadas } \\
\text { no primeiro dia de evento e receberam o } \\
\text { banco de dados para desenvolvimento dos } \\
\text { projetos. Pós-evento: seis meses de incubação } \\
\text { do startup na incubadora da Pontifícia } \\
\text { Universidade Católica de Goiás (PUC-GO). }\end{array}$ & $\begin{array}{l}\text { Apresentar ideias de melhoria da gestão } \\
\text { pública, ampliar a transparência e } \\
\text { divulgação de dados públicos do Estado } \\
\text { de Goiás. }\end{array}$ \\
\hline
\end{tabular}


Quadro 1. continuação

\begin{tabular}{|c|c|c|c|}
\hline Ano & Evento/Instituição & Especificidades metodológicas & Desafios propostos \\
\hline \multirow{5}{*}{2016} & $\begin{array}{l}\text { Hackathon Abeme }{ }^{23} \\
\text { Abeme }\end{array}$ & $\begin{array}{l}\text { Dois dias de duração; premiação: produtos; } \\
\text { inscrição individual ou de equipe (quatro } \\
\text { pessoas); acompanhamento de mentores } \\
\text { especializados das áreas específicas. }\end{array}$ & $\begin{array}{l}\text { Desenvolver de forma inovadora } \\
\text { aplicativos com fontes abertas e } \\
\text { confiáveis, sobre sexualidade e } \\
\text { prevenção, ou que conectem os jovens, } \\
\text { informando-os sobre as ações realizadas } \\
\text { pelos atores públicos e privados. }\end{array}$ \\
\hline & $\begin{array}{l}\text { Hackathon Campinas }{ }^{24} \\
\text { Municípios Associados/ } \\
\text { Prefeitura Municipal de } \\
\text { Campinas }\end{array}$ & $\begin{array}{l}\text { Dois dias de duração; premiação em dinheiro. } \\
\text { Cada equipe teve quatro pessoas (três } \\
\text { desenvolvedores e um designer); originalidade } \\
\text { das soluções como cláusula do regulamento. }\end{array}$ & $\begin{array}{l}\text { Criar aplicativos para a população usando } \\
\text { a base de dados aberta da Prefeitura de } \\
\text { Campinas. }\end{array}$ \\
\hline & $\begin{array}{l}\text { 10 Hackathon Prodam } 2016^{25} \\
\text { Secretaria de Estado } \\
\text { do Planejamento e } \\
\text { Desenvolvimento } \\
\text { Econômico, Ciência } \\
\text { Tecnologia e Inovação } \\
\text { do Amazonas e } \\
\text { Processamento de } \\
\text { Dados Amazonas S.A. }\end{array}$ & $\begin{array}{l}\text { Dois dias de duração; premiação: cursos } \\
\text { voltados para a área de TI, em qualquer lugar } \\
\text { do país; equipes interdisciplinares. }\end{array}$ & $\begin{array}{l}\text { Desenvolver aplicativos móveis } \\
\text { inovadores para os serviços públicos do } \\
\text { Amazonas. }\end{array}$ \\
\hline & $\begin{array}{l}\text { Hackathon GDG São } \\
\text { José dos Campos } \\
\text { Faculdade Bilac/Google } \\
\text { Developer Group }\end{array}$ & $\begin{array}{l}\text { Dez horas de duração; alunos dos cursos } \\
\text { de Ciência da Computação e Análise e } \\
\text { Desenvolvimento de Sistemas da Faculdade } \\
\text { Bilac. }\end{array}$ & $\begin{array}{l}\text { Desenvolver um software capaz de } \\
\text { mapear os focos do mosquito na cidade. }\end{array}$ \\
\hline & $\begin{array}{l}\text { Hackathon em Saúde }{ }^{27} \\
\text { ICICT/Fiocruz }\end{array}$ & $\begin{array}{l}\text { Dois dias de duração; premiação: cursos } \\
\text { e participação em evento; equipes de três } \\
\text { a cinco pessoas, formadas previamente } \\
\text { ou no dia do evento; etapa anterior de } \\
\text { planejamento, com programação pré- } \\
\text { hackathon, divulgação das regras do desafio, } \\
\text { modalidades de competição, critérios de } \\
\text { avaliação e premiações; tema do desafio foi } \\
\text { sorteado para cada equipe na abertura do } \\
\text { evento. Apresentação dos produtos no modelo } \\
\text { elevator pitch. }\end{array}$ & $\begin{array}{l}\text { Desenvolver aplicativos e inovações } \\
\text { tecnológicas (aplicativos móveis ou } \\
\text { games) sobre os temas Rede Global de } \\
\text { Bancos de Leite Humano; Monitoramento } \\
\text { e Controle de Vetores; NBCAL: } \\
\text { Norma Brasileira para Comercialização } \\
\text { de Alimentos para Lactentes; } \\
\text { Circuito Saudável; Acesso Aberto ao } \\
\text { Conhecimento Científico; Museu da Vida. }\end{array}$ \\
\hline
\end{tabular}

As maratonas identificadas foram realizadas por organizações sociais (três), instituições públicas (sete) - das quais duas são empresas estatais - e instituições privadas (seis). Nos eventos das organizações sociais, destaca-se a iniciativa de integração de diferentes países e o foco para questões sociais, tendo como pano de fundo o aspecto colaborativo. Ao que concerne ao grupo de instituições privadas, observamos a diversidade de empresas, sendo apenas uma do setor Saúde, e as demais vinculadas à indústria e ao ensino superior. Nesse grupo, os objetivos principais foram o desenvolvimento de aplicativos e serviços. As instituições públicas, por sua vez, apresentaram vinculação direta com a área da Saúde e a administração pública. Desse conjunto, dois eventos foram organizados pela Fiocruz, um deles em parceria com o Ministério da Saúde; outro pelo próprio Ministério da Saúde em parceria com uma universidade federal; um foi promovido por administração do executivo estadual; e outras duas maratonas por empresas estatais. No conjunto, destacam-se hackathons que visaram à acessibilidade da população às bases de dados públicos com o intuito de potencializar a cidadania, por meio de ferramentas digitais (plataforma e/ou aplicativos).

Briscoe e Mulligan² ${ }^{2}$ ropõem uma tipologia para classificação das diferentes aplicações da metodologia, dividida em dois grandes grupos: 1) hackathons com finalidade essencialmente tecnológica, organizados com o propósito de desenvolvimento de softwares; e 2) hackathons nos 
quais a tecnologia é mobilizada como recurso para construção de soluções para problemas sociais ou organizacionais. Cada um desses tipos é subdividido pelos autores em outros três. No primeiro grupo, as distinções referem-se a três possibilidades do desenvolvimento tecnológico: 1) quando uma aplicação específica é objeto de trabalho; 2) quando o foco é uma plataforma e/ou linguagem determinada; e 3) quando é definida uma interface específica de programação. No grupo dos chamados hackathons aplicados, as especificidades condizem com as finalidades do evento: se direcionadas a questões sociais; demográficas e populacionais; ou organizacionais.

Essa tipologia auxilia-nos a classificar os eventos encontrados na pesquisa, todos do grupo de hackathons aplicados, divididos entre: questões sociais (11); organizacionais (duas); e demográficas (uma), sendo um deles destinado ao público jovem. A partir dos achados, acrescentaríamos a essa classificação um quarto tipo de hackathon aplicado, que seria com finalidades educacionais. No conjunto dos eventos mapeados, dois foram organizados por instituição de ensino, tendo como público estudantes da área de tecnologia, visando aplicações de seus conhecimentos técnicos. Encontramos descrições ${ }^{3-5,7}$ que apontam para o potencial formativo dessa metodologia, que proporciona experiências de trabalho coletivo, multi e interdisciplinar. Os relatos das experiências destacam que tais maratonas proporcionam aos envolvidos a percepção de novas formas de intervenção e atuação profissional, direcionadas para a construção de respostas criativas a problemas socialmente relevantes.

Em relação à duração dos eventos, há um intervalo significativo de variação, entre dez horas e cinco dias. Não obstante, a maioria (11) dos hackathons teve entre dois e três dias de ocorrência. Três deles tiveram duração menor do que 48 horas, sendo um de dez horas, um de 24 horas e o terceiro de 36 horas. Tal composição indica haver uma tentativa de equilíbrio, de modo a preservar a intensividade da metodologia e de propiciar, por outro lado, um período de tempo adequado para formulação e desenvolvimento dos produtos. $O$ fato de que apenas dois eventos tiveram mais do que 72 horas permite-nos supor que uma maior extensão não resulta em proporcional ou maior qualificação das soluções criadas, possivelmente pela natureza intensiva e desgastante da atividade.

A literatura sobre o tema é convergente com esses resultados, indicando que a duração das maratonas hackers pode variar entre algumas horas a alguns dias, dificilmente ultrapassando uma semana ${ }^{2}$. Encontramos um relato de etapa de planejamento pré-evento no qual os participantes foram mobilizados, por meio de listas de e-mail e conferências virtuais, a fim de contribuírem com temáticas, ideias e propostas de desafios 5 . No conjunto de eventos identificados, apenas três utilizaram estratégias anteriores de mobilização dos participantes.

Das 16 maratonas encontradas, 13 possuíam caráter competitivo, o que indica ser este um aspecto usual da metodologia. Os três eventos que não o observaram foram organizados, respectivamente, por uma instituição pública e outra privada, de caráter educacional. Este último, em especial, foi o que apresentou a composição menos diversificada, com participação exclusiva de alunos da área de tecnologia da informação, sendo apoiado por empresa líder do ramo (Google), o que sugere que esse apoio é um elemento motivacional relevante ao público-alvo.

A natureza das premiações revelou-se bastante diversificada. Cinco eventos incluíram ganhos em dinheiro, sendo dois acrescidos de outros prêmios. Foram encontradas, ademais, as seguintes premiações: equipamentos (um); voucher para utilização de software (um), produtos diversificados (um), cursos (quatro), participação em evento da área para apresentação dos produtos (dois), mentorias ${ }^{(g)}$ (três), incubação dos projetos e soluções (dois) e visitas técnicas 
(um). Embora prevaleça a premiação monetária nas maratonas competitivas, observaram-se outros aspectos motivacionais, principalmente relativos ao desenvolvimento posterior das soluções criadas, qualificação profissional dos participantes e reconhecimento entre pares e no mercado. Esses dados corroboram com uma pesquisa realizada com 150 participantes de hackathons, na qual a motivação dos entrevistados para participarem dos eventos dividiu-se, basicamente, em torno do aprendizado (referido por $86 \%$ dos entrevistados) e da possibilidade de construção de redes profissionais (mencionado por $82 \%$ ). Apenas $28 \%$ referiram os prêmios como razão central de sua participação. Outro dado interessante são as respostas (38\%) que mencionam o desejo de "mudar o mundo" como motivação relevante ${ }^{2}$.

O tamanho dos eventos também foi variável. Dos 16 mapeados, um ainda não havia sido realizado, e não foi possível obter a informação do total de participantes de uma das maratonas já efetivadas. No restante (14), observamos a tendência de serem eventos menores: seis deles com menos de cinquenta pessoas e outros quatro entre cinquenta e cem. Duas maratonas contaram com a presença de cem a 150 pessoas e duas outras com mais do que esse total, tendo uma delas quinhentos participantes. Podemos aventar duas explicações, possivelmente convergentes para esses dados: por um lado, a limitação do tamanho preserva as características de informalidade e "intimidade" originárias do formato; por outro, viabilizam aspectos logísticos, fundamentais para estrutura e suporte necessários aos trabalhos.

Não obtivemos dados sociodemográficos dos participantes, o que pode constituir campo oportuno para novas investigações. Quanto a esse aspecto, uma única pesquisa foi realizada, indicando que $70 \%$ dos participantes de hackathons já haviam participado de mais de um evento desse tipo². A participação feminina foi significativamente sub-representada (em torno de $11 \%$ na pesquisa). Segundo os autores, este dado pode ser explicado pela natureza antissocial de parte dos eventos e por atitudes de gênero discriminatórias dos participantes masculinos. Entretanto, ressalta-se que os percentuais de participação feminina encontrados são similares à presença no mercado de trabalho em tecnologia. Nessa mesma investigação, destacou-se o perfil jovem dos participantes, com $61 \%$ possuindo entre 25 e 43 anos. O formato desses eventos favorece a participação deste grupo etário por requisitar disponibilidade integral nos fins de semana e trabalhos intensivos ao longo do período noturno ${ }^{2}$. De forma geral, a metodologia requer dos participantes algumas características específicas: 1) habilidade de trabalhar intensivamente sob pressão de tempo; 2) habilidade de apresentar seus trabalhos e produtos em curto espaço de tempo; e 3) capacidade de trabalhar informalmente com estranhos em pequenos grupos².

No que tange à atuação profissional dos participantes, a referida pesquisa indicou que $77 \%$ dos entrevistados se descrevem como desenvolvedores de softwares. A classificação dos demais $23 \%$ como não desenvolvedores inclui uma gama ampliada de áreas de atuação profissional, diversificação que demonstra ser particularmente relevante para os hackathons direcionados a promover contribuições para questões sociais ou objetivos empresariais², como no caso dos eventos mapeados, que apresentaram múltiplas composições profissionais.

Embora com natureza claramente tecnológica, ainda que voltados para questões da Saúde, em sua grande maioria, os hackathons mapeados previram equipes multiprofissionais. Do total de 16, não encontramos informações sobre esse aspecto nas páginas de um evento, e outro sinalizava ser aberto a qualquer área profissional. Os 14 restantes, entretanto, procuraram composições específicas, claramente direcionadas pelas características temáticas dos desafios. 13 recrutaram profissionais do setor de tecnologia, principalmente programadores e desenvolvedores, e 12 incluíram designers nas equipes. Em seguida, destaca-se o grupo relacionado à área de gestão e administração, referidos como componentes obrigatórios em nove maratonas. A designação de empreendedores sobressai neste grupo, indicando a preocupação com um perfil voltado para a inovação.

Os profissionais que compõem grupos de usuários dos produtos que foram desenvolvidos ou são especialistas em alguma temática ou foram chamados em apenas quatro eventos, incluindo categorias como profissionais de Saúde, Educação, especialistas em temas sociais e cientistas. Tal resultado evidencia que os desafios direcionados à Saúde ainda incluem pouco a participação de representantes dessa área. De modo geral, a composição das equipes evidencia a centralidade das 
áreas de tecnologia da informação, designer e gestão como elementares do processo criativo, o que demonstra a preocupação em qualificar o desenvolvimento tecnológico com aspectos na interface entre apresentação, usabilidade e plano de negócios. Poderíamos, com isso, demarcar a necessidade de investigar melhor os efeitos da inclusão dos profissionais da área de Saúde nas equipes de desenvolvimento. Inferimos que a ampliação da presença deles potencializaria a adequação dos produtos às demandas iniciais.

Sete maratonas previam estratégias para o desenvolvimento posterior dos projetos, o que corrobora a sinalização da literatura sobre o foco das maratonas, consideradas produtivas para etapa de concepção (protótipos), mas limitadas para qualificação e operacionalização das propostas formuladas². No tocante à avaliação, cinco hackathons não divulgaram em suas respectivas páginas e regulamentos a composição do júri ou os critérios avaliativos. Apenas um fez a divulgação nominal nos componentes da banca avaliadora, e outro indicou sua composição profissional, espelhada na composição das equipes formadas no evento.

Os critérios de avaliação elencados podem ser agrupados em seis subconjuntos, referentes às seguintes características dos produtos: 1) Utilidade e adequação ao desafio proposto; 2) Inovação; 3) Qualidade técnica; 4) Viabilidade; 5) Experiência do usuário; e 6) Execução da solução, descritos sob diferentes designações, conforme apresentado no Quadro 2.

Quadro 2. Critérios de avaliação das soluções criadas em hackathons realizados no Brasil com desafios no campo da Saúde

\begin{tabular}{|c|c|c|}
\hline Temática central & Descrições encontradas & $\begin{array}{l}\text { Número de maratonas que incluíram } \\
\text { critérios com essas temáticas }\end{array}$ \\
\hline $\begin{array}{l}\text { Utilidade e } \\
\text { adequação }\end{array}$ & $\begin{array}{l}\text { Interesse público/Utilidade/Impacto social/Alcance da solução/ } \\
\text { Adequação da solução ao desafio proposto }\end{array}$ & 7 \\
\hline Inovação & $\begin{array}{l}\text { Criatividade (3)/Originalidade/Grau de inovação (2)/Conceito/ } \\
\text { Design (3)/Originalidade/Disruptividade da inovação }\end{array}$ & 12 \\
\hline Qualidade técnica & $\begin{array}{l}\text { Qualidade técnica/Dificuldade tecnológica/Integração da } \\
\text { plataforma de Ambiente Virtual de Aprendizagem (AVA)/ } \\
\text { Tecnologias utilizadas/Qualidade do código (clareza, } \\
\text { modularização, facilidade de manutenção e documentação) }\end{array}$ & 5 \\
\hline Viabilidade & $\begin{array}{l}\text { Aplicabilidade/Viabilidade de execução real da solução } \\
\text { tecnológica apresentada }\end{array}$ & 4 \\
\hline $\begin{array}{l}\text { Experiência do } \\
\text { usuário }\end{array}$ & $\begin{array}{l}\text { Usabilidade (interação, motivação)/Interação com o público, } \\
\text { comunicabilidade/Experiência do usuário }\end{array}$ & 3 \\
\hline $\begin{array}{l}\text { Grau de execução } \\
\text { da solução }\end{array}$ & $\begin{array}{l}\text { Maturidade do projeto (interação das telas, exploração do } \\
\text { tema, usabilidade)/Execução }\end{array}$ & 2 \\
\hline
\end{tabular}

Segundo a literatura, a avaliação frequentemente é realizada por especialistas convidados e/ou organizadores, como encontrado nos resultados desta pesquisa. O julgamento dos produtos é visto como fator relevante na dinâmica dos eventos, variando o grau de estruturação prévia dos critérios. Alguns dos critérios considerados pertinentes em geral são a exequibilidade dos projetos em termos de seu desenvolvimento posterior; a dificuldade técnica e a qualidade dos produtos; a criatividade e originalidade das soluções e a adequação e/ou usabilidade em relação ao seu público-alvo ${ }^{3,4}$. A organização do julgamento foi um dos pontos que a literatura indicou necessidade de especial atenção, no sentido de garantir critérios formalizados de maneira adequada, e uma condução que ressalte os aspectos positivos da experiência².

Nos critérios sistematizados na tabela, observamos maior concentração na originalidade das soluções, sendo que vários eventos previam no regulamento o plágio (parcial ou integral) e a ausência de ineditismo (soluções já formuladas e/ou comercializadas antes do evento) como critérios para o rompimento contratual e cancelamento da participação. No polo oposto, a experiência do usuário, ainda que considerada, possuiu menor peso no conjunto dos critérios identificados, juntamente com o 
grau de execução do produto. Este último foi o critério menos explicitado, o que correlacionamos com o foco dos eventos na etapa de formulação das soluções.

Os eventos mapeados possuíram programação e organização bastante diversificadas, em consonância com trabalho de revisão encontrado sobre a metodologia ${ }^{2}$. Apesar da variabilidade, é frequente que as maratonas iniciem com apresentações sobre a proposta, esclarecendo sobre os objetivos, metodologia e prêmios, quando disponíveis. Metas e desafios tanto podem ser expostos no início quanto previamente, dependendo da metodologia empregada. Embora menos frequente, também se observa a possibilidade de que sejam elaborados no próprio evento².

Uma das maratonas mapeadas compunha uma estratégia de internacionalização de um dos hackathons internacionais mais tradicionais, intitulado Campus Party e organizado pela empresa Futura Networks desde 1997, na Espanha. Dois explicitaram que a maratona previa atividades ininterruptas, corroborando o imaginário que caracterizou os eventos iniciais, marcados pela intensividade das atividades que favorece contatos menos superficiais e formais, gerando oportunidades de inserção em redes de trabalho (networks) e ampliando possibilidades de conhecer e colaborar na criação de novos projetos, de médio e longo prazo ${ }^{3}$.

No tocante à formação das equipes, encontramos estratégias diferentes, todas já descritas nos relatos de experiência anteriores ${ }^{1,2,5}$, que indicam que hackathons aplicados tendem a incluir seleção prévia dos participantes, balizada por sua expertise nas temáticas em foco. A formação das equipes é considerada uma das etapas centrais da metodologia, necessariamente presente nos diferentes arranjos, uma vez que constitui o núcleo do trabalho colaborativo. Podem ser definidos ou sugeridos pela organização o tamanho e características dos grupos, ou mesmo a composição das equipes. Quando estes são formados no evento, é frequente que sejam agrupados em torno de propostas e ideias compartilhadas, baseado em interesses e habilidades individuais ${ }^{2,7}$. Nesse caso, a programação reserva momento específico para os participantes proporem, selecionarem e aderirem a propostas de desenvolvimento ${ }^{5}$.

A programação incluiu atividades para conhecimento das demandas embasadoras dos desafios, palestras, tempestades de ideias, discussão dos grupos com convidados e organizadores, momentos para composição das equipes e recursos de relaxamento de grupo como estratégia para intervir na dinâmica das equipes e na concentração dos participantes. A apresentação pública dos resultados foi valorizada, sendo inclusive tratada como aspecto da premiação em duas maratonas, o que sugere o reconhecimento social e técnico como elemento motivacional importante. Esse aspecto também foi abordado por Linnel et al. ${ }^{3}$, que enfatizam que a apresentação pública proporciona o compartilhamento, aprendizagem coletiva e reconhecimento social dos envolvidos. Além dessas características, destaca-se o recurso ampliado à mentoria, um tipo de orientação de profissional qualificado ofertado aos grupos pela organização.

\section{Considerações finais}

Os resultados encontrados no mapeamento da realização de hackathons com desafios voltados para o campo da Saúde evidenciam o crescimento desses eventos no Brasil a partir de 2012. De modo geral, os elementos e caraterísticas neles identificados reforçam o potencial da metodologia, em particular por possibilitar unir vários atores, principalmente das áreas de tecnologia, gestão e comunicação, aproximando-os de problemas sociais e empresariais da saúde.

O trabalho colaborativo e intensivo durante as maratonas, unindo várias expertises em equipes, parece realmente potencializar o surgimento de ideias criativas para solucionar problemas e/ou qualificar políticas, programas e estratégias da gestão pública e empresarial na saúde. Ressaltouse, contudo, participação pouco expressiva de profissionais de Saúde nesses eventos, o que pode ser melhor investigado e incentivado, a fim de compreendermos o impacto de sua participação na qualidade e adequação das soluções criadas.

Em síntese, os resultados corroboram a percepção de que as maratonas hackers promovem em essência o desenvolvimento tecnológico, em espaço dinâmico e com amplo potencial criativo. 
Ponderamos, contudo, sobre a importância de um desenho bem definido referente ao desafio, uma vez que as maratonas hackers são atividades que requerem clara orientação. Nesse sentido, o redirecionamento e ampliação do potencial desse evento não sugere simplesmente um empréstimo das maratonas hackers pelas outras áreas de atuação, mas também a necessidade de escolha de estratégias metodológicas específicas, direcionadas pelos objetivos traçados. Não obstante, algumas características foram confirmadas como estruturantes da metodologia: o trabalho colaborativo, a intensividade, a informalidade, o foco na inovação e na aplicação e desenvolvimento tecnológico. Em menor medida, a competitividade também pode ser destacada.

Observamos que os hackathons são capazes de promover um diálogo entre as áreas, propiciando uma visão multifacetada das questões colocadas pelo desafio. Esse fator permite um ambiente favorável ao próprio aspecto criativo, que amplia a capacidade inovadora para os produtos elaborados nas maratonas. Além disso, a metodologia parece possuir interessante potencial formativo, na medida em que tem como elementos centrais a colaboração e a inovação, o que é particularmente importante quando empregadas em desafios com grande relevância social. Essas características revelam-se oportunas à formação profissional em Saúde, que encontra como um de seus grandes desafios o trabalho em equipes multiprofissionais e a construção de autonomia criativa no enfrentamento de problemas constituídos por complexas determinações sociais.

\section{Colaboradores}

Francini Lube Guizardi e Karina Fernandes trabalharam na concepção do projeto, coleta e análise dos dados, discussão dos resultados, redação e aprovação final do texto. Ana Silvia Pavani Lemos e Fernanda Maria Duarte Severo contribuíram na redação, discussão dos resultados, revisão e aprovação final do texto.

\section{Referências}

1. McArthur K, Lainchbury H, Horn D. Guia para hackathon de dados abertos. Tradução Angeluci A [Internet]. 2012 [citado 15 Mai 2016]; Disponível em: http://www.acessasp. sp.gov.br/wp-content/uploads/2015/03/Como-fazer-um-hackathon.pdf.

2. Briscoe G, Mulligan C. Digital innovation: the hackathon phenomenon. London: CreativeWorks LondonWorking Paper; 2014.

3. Linnell N, Figueira S, Chintala N, Falzarano L, Ciancio V. Hack for the homeless: a humanitarian technology hackathon. In: Global Humanitarian Technology Conference (GHTC); 10-13 Oct 2014; San Jose, USA. San Jose: IEEE; 2014. 577.

4. Li LM, Johnson S. Hackathon as a way to raise awareness and foster innovation for stroke. Arq Neuropsiquiatr. 2015; 73(12):1002-4.

5. Stoltzfus A, Lapp H, Matasci N, Deus H, Sidlauskas B, Zmasek CM, et al. Phylotastic! Making tree-of-life knowledge accessible, reusable and convenient. BMC Bioinformatics. 2013; 14(158):1-17.

6. Walker A, Ko N. Bringing medicine to the digital age via hackathons and beyond. J Med Syst. 2016; 40(4):98. 
7. Aungst TD. Using a hackathon for interprofessional health education opportunities. J Med Syst. 2015; 39(5):60.

8. OpenBSD. Hackathons [Internet]. [citado 22 Jul 2016]. Disponível em: https://www. openbsd.org/hackathons.html.

9. D'Ignazio C, Hope A, Metral A, Zuckerman E, Raymond D, Brugh W, et al. Hacking the hackathon with breast pumps and babies [Internet]. J Peer Prod. 2016; 8:1-25 [citado 22 Jul 2016]. Disponível em: http://peerproduction.net/wp-content/uploads/2016/03/ Hacking-the-hackathon-draft.pdf.

10. The Homebrew Computer Club [Internet]. Mountain View (CA): Computer history museum; 2016 [citado 05 Ago 2016]. Disponível em: http://www.computerhistory.org/ revolution/personal-computers/17/312.

11. Wozniak S. Homebrew and how the apple came to be [Internet]. Atariarchives.org [citado 05 Ago 2016]. Disponível em: http://www.atariarchives.org/deli/homebrew_and_ how_the_apple.php.

12. Bormann R. Desarrollando América Latina, el último hackatón del año. Blogs Infobae [Internet]. Buenos Aires: Infobae.com; 2012 [citado 10 Abr 2016]. Disponível em: http:// blogs.infobae.com/gobierno-abierto/2012/11/26/dal2012-desarrollando-america-latinael-ultimo-hackaton-del-ano/.

13. Leite C. Aplicativo Recife Saúde vence o torneio Hacker Cidadão. JC Online [Internet]. 2013 [citado 10 Abr 2016]. Disponível em: http://jconline.ne10.uol.com.br/ canal/tecnologia/noticia/2013/07/20/aplicativo-recife-saude-vence-o-torneio-hackercidadao-90786.php.

14. Federação das Indústrias do estado de São Paulo. $2^{\circ}$ Hackathon CJE FIESP [Internet]. São Paulo: FIESP; 2014 [citado 15 Abr 2016]. Disponível em: http://www.fiesp.com.br/ agenda/2o-hackathon-cje-fiesp/

15. Fundação Oswaldo Cruz. Fiocruz Brasília sedia 'hackathon', maratona sobre inovação e conhecimento em saúde [Internet]. Brasília: Fiocruz; 2014 [citado 15 Abr 2016]. Disponível em: http://portal.fiocruz.br/pt-br/content/1o-hackathon-para-gestao-do-conhecimentoem-saude-e-realizado-na-fiocruz-brasilia.

16. Federação das Indústrias do estado de São Paulo. $3^{\circ}$ Hackathon CJE FIESP [Internet]. São Paulo: FIESP; 2014 [citado 15 Abr 2016]. Disponível em: http://www.fiesp.com.br/ agenda/3o-hackathon-cje-fiesp/

17. Venturini J. Conheça os projetos que podem transformar a realidade latinoamericana premiados pelo DAL 2014 [Internet]. Cambridge: Open Knowledge Brasil; 2014 [citado 15 Abr 2016]. Disponível em: http://br.okfn.org/2014/12/17/conheca-os-projetos-quepodem-transformar-a-realidade-latinoamericana-premiados-pelo-dal-2014/

18. HackPUC [Internet]. Rio de Janeiro: PUC Rio; 2014 [citado 15 Abr 2016]. Disponível em: https://www.passeidireto.com/hackpuc/.

19. Ministério da Saúde (BR). HackSUS: Comunidade de práticas [Internet]. Brasília: Ministério da Saúde; 2015 [citado 20 Abr 2016]. Disponível em: https://ajuda. atencaobasica.org.br/hacksus/

20. Guedes S. Hackathon busca soluções digitais para os setores de saúde e eventos [Internet]. Brasília: Agência Sebrae de Notícias; 2015 [citado 20 Abr 2016]. Disponível em: http://www.mg.agenciasebrae.com.br/sites/asn/uf/MG/hackathon-busca-solucoesdigitais-para-os-setores-de-saude-e-eventos.

21. Hospital Innovation Show. Hackathon Hack4Health [Internet]. São Paulo: HIS; 2015 [citado 20 Abr 2016]. Disponível em: http://saudebusiness.com/his/2015/event/ hack4health/ 
22. Lopes I. Goiás estimula empreendedorismo do estado através de Hackathonda transparência [Internet]. São Paulo: Canaltech; 2015 [citado 20 Abr 2016]. Disponível em: https://corporate.canaltech.com.br/materia/startups/goias-estimula-empreendedorismodo-estado-atraves-de-hackathona-da-transparencia-54923/

23. Associação Brasileira das Empresas do Mercado Erótico e Sensual. Hackathon ABEME [Internet]. São Paulo: ABEME; 2016 [citado 20 Abr 2016]. Disponível em: http:// hackathonabeme.blogspot.com.br/2016.

24. Prefeitura Municipal de Campinas. Informática de Municípios Associados e Sensedia. Hackathon Campinas/SP [Internet]. Campinas: IMA; 2016 [citado 20 Abr 2016].

Disponível em: http://hackathon.ima.sp.gov.br/

25. PRODAM. Governo do Estado do Amazonas. Prodam realiza I Hackathon PRODAM 2016 [Internet]. Manaus: PRODAM; 2016 [citado 20 Abr 2016]. Disponível em: http:// www.prodam.am.gov.br/2016/02/26/prodam-realiza-i-hackathon-prodam-2016/.

26. Agência de Imprensa. Aplicativo desenvolvido por alunos irá mapear os focos de dengue em São José dos Campos [Internet]. São José dos Campos: Al; 2016 [citado 20 Abr 2016]. Disponível em: http://agenciadeimprensa.com.br/site/2016/04/aplicativodesenvolvido-por-alunos-ira-mapear-os-focos-de-dengue-em-sao-jose-dos-campos/.

27. Fundação Oswaldo Cruz. Hackathon em Saúde: Maratona de desenvolvimento de aplicativos e inovações tecnológicas para o SUS [Internet]. Brasília: IBICT/Fiocruz; 2016 [citado 24 Out 2016]. Disponível em: http://hackathon.icict.fiocruz.br/.

Guizardi FL, Santos KF, Lemos ASP, Severo FMD. Maratones hackers en Brasil con desafíos en el campo de la Salud. Interface (Botucatu). 2018; 22(65):447-459.

El objetivo de este estudio fue mapear la realización de maratones hackers en Brasil, con desafíos enfocados en el campo de la Salud. Se espera que la descripción y sistematización de los aspecto metodológicos de los eventos identificados, comparados con informaciones provenientes de investigación bibliográfica, auxilien en la divulgación y aplicación de la metodología en la Salud. De carácter exploratorio y descriptivo, el mapeo se realizó por medio de una investigación web, con el buscador Google, y en la base de datos Biblioteca Virtual de la Salud (BVS), incluyendo el período entre 2000 y 2016 . Se identificó la realización de 16 hackathons que abordaron desafíos o soluciones en la Salud, todos ellos realizados a partir de 2012. Los resultados encontrados subrayan el potencial de la metodología como fomento a la creatividad y a la innovación a partir del trabajo colaborativo en equipo multi-profesional para soluciones oportunas en el campo de la Salud.

Palabras clave: Hackathon. Metodología. Salud. Colaboración. Innovación en Salud. 
